\title{
ПОЧЕЧНАЯ ГЛЮКОЗУРИЯ, ОБУСЛОВЛЕННАЯ ГЕТЕРОЗИГОТНОЙ МУТАЦИЕЙ В ГЕНЕ SLC5A2 У ПАЦИЕНТКИ С САХАРНЫМ ДИАБЕТОМ ТИПА МОDY2.
}

\author{
Романенкова Е.М., Зубкова Н.А.
}

ФГБУ «Национальный медицинский исследовательский центр эндокринологии» Министерства здравоохранения Российской Федерации, Россия, Москва Ключевые слова: MODY, гипергликемия, почечная глюкозурия.

Актуальность: Дифференциальная диагностика моногенных форм сахарного диабета базируется на отягощенном семейном анамнезе, клиническом течении заболевания, отсутствии специфических аутоантител. Сочетание непрогрессирующей гипергликемии с глюкозурией клинически позволяет предположить наличие у пациента сахарного диабета типа MODY3. Однако, почечная глюкозурия возможна и при ряде иных патологических состояний, как ассоциированных с гипергликемией, так и изолированно. Представляем семейный случай гипергликемии с глюкозурией, обусловленный сочетанием мутаций в генах $G C K$, обуславливающий развитие сахарного диабета типа MODY2 и $S L C 5 A 2$, приводящих к развитию почечной глюкозурии.

Клинический случай. Пробанд. При рождении (беременность на фоне ГСД, роды на 37 неделе) рост 2680 гр (-0,48 SD), масса тела 51 см (1,48 SD). Впервые повышение гликемии до 6,5 ммоль/л натощак выявлено в 5 лет. В рутинных анализах мочи периодически фиксировалась глюкозурия, кетоны. При обследовании в возрасте 7,9 лет: ОГТТ 7,36-6,64 ммоль/л, НвА1с 6\%, С-пептид 0,89 нг/мл $(1,1-4,4)$, инсулин 1,24 мкЕд/мл (1,9 -23), глюкозурия 28 ммоль/л (N: 0-0,1). При обследовании в ФГБУ «НМИЦ эндокринологии» в возрасте 8,7 лет: рост: 124.0 см (-1.06 SD), вес: 25.3 кг, ИМТ 16.5 кг/м2 (+ 0.3 SD). Гликемия натощак максимально 7,5 ммоль/л, после еды до 9,8 ммоль/л. При ОГТТ показатели гликемии в пределах нормы (натощак 5,7 ммоль/л, 120 мин 6,3 ммоль/л), базальная и стимулированная секреция инсулина сохранны, глюкозурия 6,0 ммоль/л (0-2,8), НвA1с 6,9 \%, аутоантитела IA2 и GADA- отрицательные.

Наследственный анамнез отягощен в 4-х поколениях по материнской линии. Прадед, 78 лет, СД с 35 лет, ПССП. Бабушка, 57 лет, гипергликемия с 17 лет (ИМТ 26 кг/м2) до 6,3 ммоль/л, НТГ. Во время 1 беременности (21 год) назначена инсулинотерапия, которую получала до 36 лет с последующим переводом на гликведон, на фоне которого отмечались гипогликемии. С 36 лет терапию не получает, динамически не обследована. У матери пробанда 27 лет (ИМТ 20,8 кг/м2), глюкозурия с 5 лет, гипергликемия натощак до 7,8 ммоль/л, ГСД без соблюдения диеты, НвА1с максимально 7,3\%, базальная секреция инсулина сохранна (С-пептид 1,43 нг/мл), периодически глюкозурия, титры АТ к GADA, IAA, ICA, IA2, Znt8-отрицательные. Тетя пробанда, 22 года, ГСД первой беременности.

В ходе молекулярно-генетического исследования методом NGS у матери и ребенка в гене $G C K$ (NM_138079) выявлен комплексный вариант в гомозиготном состоянии с.46-15 4611delCCCCTinsGGGAGGG, обуславливающий характерную для MODY2 непрогрессирующую гипергликемию. Однако, выявленный нуклеотидный вариант не объяснял причины глюкозурии. В этой связи дополнительно проведен поиск мутаций в гене SLC5A2 (NM_182381). У матери и ребенка выявлена замена c.289G>A (p.Gly97Arg) в гетерозиготном состоянии, приводящая к развитию изолированной почечной глюкозурии.

Заключение: Впервые приводится описание сочетания нуклеотидных изменений в генах $G C K$ и $S L C 5 A 2$, изолированно обуславливающих развитие гипергликемии и глюкозурии. В настоящем сообщении подчеркивается важность тщательной клинической оценки всех случаев моногенных форм сахарного диабета. В случае отсутствия корреляции генотип-фенотип возможен поиск нуклеотидных изменений в других генах-кандидатах, обуславливающих клинические проявления заболевания. 